\title{
Knockout of the folate transporter folt-1 causes germline and somatic defects in C. elegans
}

\author{
Misa U Austin1, Wei-Siang Liau1,2, Krishnaswamy Balamurugan,3,4, Balasubramaniem Ashokkumar3,4, Hamid M Said3,4 \\ and Craig W LaMunyon*1
}

\begin{abstract}
Background: The C. elegans gene folt-1 is an ortholog of the human reduced folate carrier gene. The FOLT-1 protein has been shown to transport folate and to be involved in uptake of exogenous folate by worms. A knockout mutation of the gene, folt-1 (ok1460), was shown to cause sterility, and here we investigate the source of the sterility and the effect of the folt-1 knockout on somatic function.

Results: Our results show that folt-1(ok1460) knockout hermaphrodites have a substantially reduced germline, generate a small number of functional sperm, and only rarely produce a functional oocyte. We found no evidence of increased apoptosis in the germline of folt- 1 knockout mutants, suggesting that germline proliferation is defective. While folt-1 knockout males are fertile, their rate of spermatogenesis was severely diminished, and the males were very poor maters. The mating defect is likely due to compromised metabolism and/or other somatic functions, as folt-1 knockout hermaphrodites displayed a shortened lifespan and elongated defecation intervals.

Conclusions: The FOLT-1 protein function affects both the soma and the germline. folt-1 (ok1460) hermaphrodites suffer severely diminished lifespan and germline defects that result in sterility. Germline defects associated with folate deficiency appear widespread in animals, being found in humans, mice, fruit flies, and here, nematodes.
\end{abstract}

\section{Background}

Folate, a member of the B-class of water-soluble vitamins, plays a major role in one-carbon-metabolism that produces nucleotides and several amino acids including methionine [1-3]. Methionine is a substrate for DNA methylation [4], which is an important regulatory mechanism for gene expression during development [5]. Folate is therefore critical to DNA and its expression, but mammals and other multicellular eukaryotes are devoid of the cellular machinery to synthesize folate [6] and must instead rely on active uptake from dietary sources. At the cellular level, three different systems are responsible for folate uptake: the folate receptors [7], the reduced folate carrier (RFC) [8], and the proton coupled folate transporter (PCFT) [9]. The reduced folate carrier is a major folate transport system in mammalian cells and plays an important role in cell growth and development [10].

\footnotetext{
* Correspondence: cwlamunyon@csupomona.edu

1 Department of Biological Sciences, California State University Pomona, CA 91768, USA

Full list of author information is available at the end of the article
}

Folate deficiency, particularly during embryogenesis, can result in a number of developmental defects. In humans, the defects include neural tube deformities [11], anemia [12], cardiovascular abnormalities [13,14], and even cancer [15]. Supplementation with dietary folate during pregnancy is effective in preventing the incidence of neural tube defects by approximately $70 \%[16,17]$. Additionally, genetic variation in the human RFC gene (hRFC) may influence the incidence of folate deficiency defects. Studies have shown that individuals homozygous for a polymorphism (A80G) in hRFC have a slightly higher risk of neural tube defects $[18,19]$ and benefit more from folate supplementation $[20,21]$. However, a more comprehensive study of six genes involved in folate metabolism found that the risk associated with the A80G polymorphism appears to stem from an interaction with a polymorphism in cystathionine $\beta$-synthase [22], a gene involved in the production of cystathionine from homocysteine [23], suggesting a complex set of interactions between RFC and other folate metabolism genes. More universally, it now appears that severe folate deficiency produces embryonic failure in a diversity of species. 
Mouse embryos die early in development when they are homozygous for an RFC1 knockout allele [24,25], and folate supplementation only delays embryonic death for several days. Females of the fruit fly Drosophila melanogaster exposed to the folate analog methotrexate are sterile due to reduced oogenesis and embryonic lethality [26]. Finally, knockout of the folate transporter folt-1 in the nematode Caenorhabditis elegans induces hermaphrodite sterility [27]. These results suggest a widespread dependency on folate for embryonic development.

We have recently cloned and functionally characterized folt-1 from C. elegans. This hRFC orthologue transports folate via a specific uptake process that is shared with other folate analogues but not with other water-soluble vitamins (thiamin, biotin and ascorbic acid). Further, transport of folate via the folt-1 system is $\mathrm{Na}^{+}$-independent, $\mathrm{pH}$-dependent, and DIDS- and sulfasalazine-sensitive. Highest expression of folt-1 was found in the pharynx and intestine of adult C. elegans, and this uptake system was found to be under both adaptive and developmental regulation. Knocking out of folt-1 leads to a significant inhibition in folate uptake with the homozygous mutants being largely sterile (C. elegans gene knockout consortium, Oklahoma Medical Research Foundation, Oklahoma City, OK) [27]. The basis of sterility, however, is not known. Also unknown is the effect of this knockout on the nematode soma. We addressed both of these issues in the current study. Our results showed the cause of sterility to be due to defects in germline proliferation, and that the folt-1 knockout also leads to diminished $C$. elegans life span and metabolism.

\section{Results}

folt-1 hermaphrodite sterility is due to a germline defect

folt-1 knockout hermaphrodites are largely sterile. Examined microscopically, we generally found no fertilized eggs, or even unfertilized oocytes, within knockout hermaphrodites. However, nearly a third of knockout hermaphrodites produce a small brood, averaging 7.2 progeny $(\mathrm{SEM}=1.1 ; \mathrm{N}=66)$, which are themselves sterile. Mutant hermaphrodites produce sperm that were all confined to the spermathecal regions (Fig. 1A), indicating that the knockout hermaphrodites produce motile sperm that can navigate normally. However, folt-1 knockout hermaphrodites produced significantly fewer sperm than those produced by either folt-1/+ heterozygotes or wildtype hermaphrodites from strain N2 (Fig 1B; $F_{2,152}=$ 410.87; $P=0.001$ ). There was no significant difference between sperm production in folt-1/+ heterozygotes and wild-type, indicating that the folt-1(ok1460) mutation is recessive for sperm production (Fisher LSD post hoc analysis: $P=0.134$ ). Figure $1 \mathrm{~B}$ shows sperm present in hermaphrodites on the first and second days of adulthood. The number of sperm is smaller on the second day for both folt-1/+ heterozygotes and for wild-type worms, reflecting sperm usage for fertilizations. Sperm numbers actually increased on the second day for folt-1 knockout mutants, a significant difference compared to the other two strains (strain $\times$ day: $F_{2,152}=7.498 ; P=0.001$ ). Not only are the sperm unused, they are still being produced well into adulthood, suggesting that gametogenesis proceeds more slowly in folt-1 knockout mutants.

While spermatogenesis is attenuated in folt-1 knockout hermaphrodites, oogenesis was nearly absent. The rare oocytes produced by the mutants typically failed to develop into offspring. This failure was not due to a lack of normal sperm, because mating with wild type males did not rescue folt-1 hermaphrodite sterility (Table 1). The males in this experiment transferred numerous sperm to the folt-1 hermaphrodites, as shown in Fig. 2.

The C. elegans hermaphrodite reproductive tract has two independent arms, each containing a region of densely packed syncytial nuclei. The nuclei in the most distal zone are mitotic, while those in the more proximal zone have entered the meiotic pachytene stage with a transitional zone in between (Fig. 3) [28]. The volumes of the three zones were significantly different among the strains examined (Fig. 4; Mitotic: F2,24 $=53.4 ; \mathrm{P}<0.001$; Transition: F2,24 = 44.6; P < 0.001; Pachytene: F2,24 = 86.9; $\mathrm{P}<0.01$ ). All three zones of the folt-1 knockout mutants were significantly smaller than those of either $\mathrm{N} 2$ or the folt- $1 /+$ heterozygotes at $\mathrm{P}=0.001$ by Bonferroni post hoc tests. N2 and folt-1/+ heterozygotes differed significantly only in the volume of the Pachytene zone; folt-1/+ heterozygotes had a larger Pachytene zone $(\mathrm{P}=0.001$, Bonferroni post hoc test $)$.

The folt-1 knockout therefore reduces the presence of germ nuclei. This reduction could be due to a slower rate of nuclear division. Alternatively, the reduction could be due to a greater rate of apoptosis, which occurs normally in the C. elegans hermaphrodite reproductive tract [29]. To distinguish these two possibilities, we examined apoptosis in the hermaphrodite reproductive tract. We determined the number of nuclei undergoing apoptosis using dyes that label apoptotic nuclei in the reproductive tract [29]. Both N2 $(\mathrm{n}=16)$ and folt-1/+ heterozygotes $(\mathrm{n}=22)$ had on average 1.5 apoptotic nuclei, but folt-1 knockout mutants $(\mathrm{n}=30)$ contained significantly fewer apoptotic nuclei, averaging $0.1\left(F_{2,65}=17.06 ; P<0.001\right)$. Therefore, folt-1 knockout mutants appear to have a defect in the germline proliferation that populates the reproductive tract with germ nuclei.

\section{folt-1 knockout males are fertile but suffer germline and mating defects}

folt-1 knockout males are capable of siring progeny, but they are not as fertile as wild-type males. We tested the ability of knockout males to sire progeny in two mating 

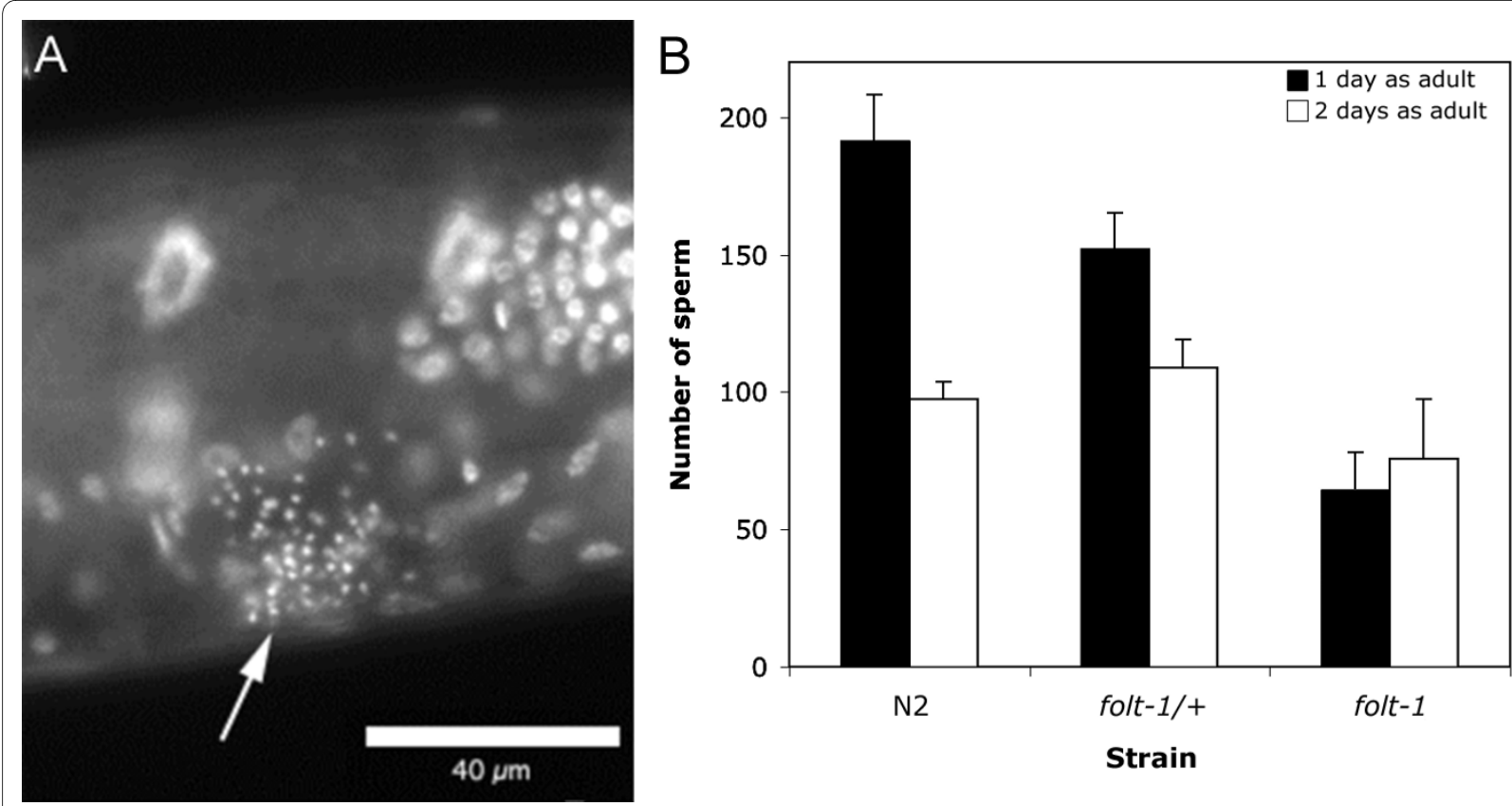

Figure 1 Sperm production by folt-1 knockout hermaphrodites. (A) The spermathecal region of a folt-1 knockout hermaphrodite is shown under epifluorescence after labeling the nuclei with DAPI. The hermaphrodite had been isolated as an L4 larva two days prior. The arrow indicates the compact sperm nuclei that are present in the region of the spermatheca. (B) The number of sperm present within both arms of the reproductive tracts were tallied in homozygous folt- 1 knockout hermaphrodites $(n=23)$, folt-1/+ heterozygotes $(n=26)$, and N2 hermaphrodites $(n=30)$ on the first and second days of adulthood. Error bars represent 1 SEM.

densities: (i) four knockout males to one fer-1(hc13ts) hermaphrodite, and (ii) one knockout male to $10 \mathrm{fer}$ 1(hc13ts) hermaphrodites for two days in both experiments (Table 1; the fer-1(hc13ts) mutation incapacitates sperm when worms are reared at $25^{\circ} \mathrm{C}$, but fer- 1 mutant hermaphrodites will become fertile if mated with fertile males [30]). In both experiments the knockout males sired progeny: nearly 70 progeny when four folt-1; him-14 knockout males mated with a single fer-1 hermaphrodite mated, but only ca. 15 offspring when one knockout male was paired with 10 hermaphrodites (Table 1). These results clearly show that the folt-1(ok1460) mutation does not prevent the production of functional sperm in males. However, control males paired with 10 fer- 1 hermaphro- dites sired nearly four times as many progeny compared to the knockout males (Table 1).

We investigated the reduced cross progeny sired by folt-1 knockout males. First, we assayed mating efficiency. Knockout males spend significantly less time in copula than do males heterozygous for the folt-1 knockout mutation (Fig. $5 ; t=2.06, P=0.003$ ). Because mating efficiency is severely impacted by defects in the male tail [31], we investigated tail morphology. Tail morphology is not the cause of reduced male fertility, because the tails of knockout males $(\mathrm{n}=16)$ appeared identical to those of control males $(n=14$; Fig. 6). Finally, we determined the rate of sperm production in knockout males. Wild-type males that have been adult for one day are known to produce

Table 1: The effect of mating for folt-1 knockout hermaphrodites and males.

\begin{tabular}{|c|c|c|c|c|c|}
\hline \multicolumn{6}{|c|}{ Cross progeny production after mating } \\
\hline Hermaphrodite genotype & Male genotype & Male:Herm. Ratio & Mean no. progeny & SEM & $N$ \\
\hline folt-1 & N2 & $4: 1$ & 0 & 0.0 & 14 \\
\hline fer-1 & folt-1; him-14 & $4: 1$ & 65.9 & 27.0 & 11 \\
\hline fer-1 & folt-1; him-14 & $1: 10$ & 15.9 & 10.9 & 15 \\
\hline fer-1 & him-14 & $1: 10$ & 49.8 & 12.6 & 15 \\
\hline
\end{tabular}

The him-14(it144)II mutation was used to obtain males with the folt-1(ok1460) knockout mutation. Unmated hermaphrodites that are him-14 mutants produce male progeny [59]. 


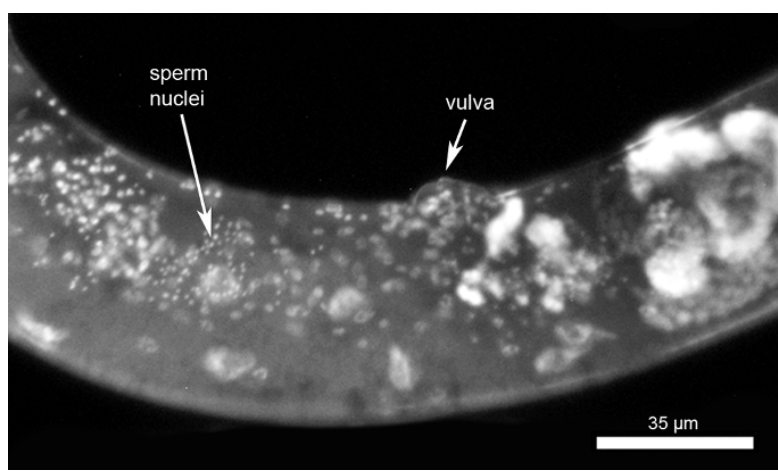

Figure 2 A mated folt-1 hermaphrodite labeled with DAPI. The arrow indicates location of numerous sperm within the uterus. These sperm were transferred from the mating male(s).

sperm at a rate of nearly 60 per hour [32]. We tallied the numbers of sperm within the reproductive tracts of folt-1 knockout males and folt-1/+ heterozygote males at two ages: the adult molt and one hour past the adult molt (Fig. 7). Comparing the sperm numbers at the two time points indicates that the folt-1/+ heterozygote males produced wild type numbers of sperm, averaging 51 per hour, but homozygous folt-1 knockout males produced only 3 sperm per hour, a difference that was significant (strain $\times$ age interaction: $F_{1,33}=5.56, P=0.024$ ).

\section{folt-1 worms have reduced longevity and metabolism}

Because folt-1 worms lay very few eggs and have reduced production of germ nuclei, we wondered if they might be compromised metabolically. We first measured the rate of defecation, which is sensitive to variations in energy metabolism [33]. folt-1 knockout worms defecated at a significantly reduced rate compared to folt-1/+ heterozygotes and to wild type $\left(F_{2,33}=44.48, P<0.001\right.$; Fig. 8$)$. Because defecation rates suggested that folt-1 knockout mutants experienced reduced metabolism, we wondered

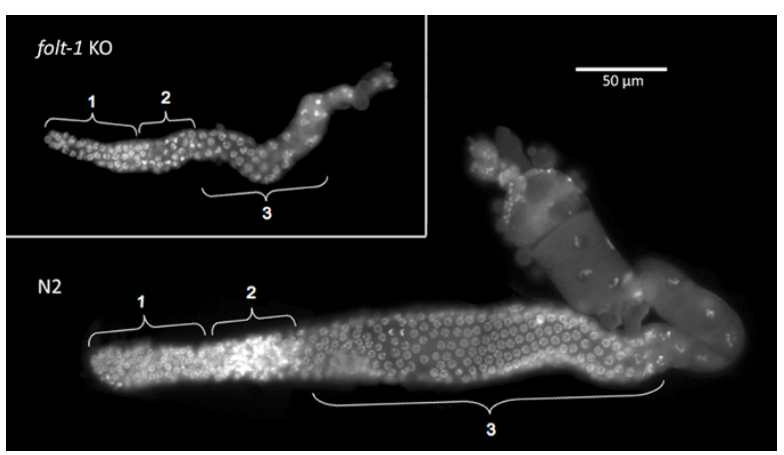

Figure 3 Germ nuclei in the reproductive tracts of hermaphrodites. The $\mathrm{N} 2$ reproductive tract on the bottom shows nuclei in the mitotic phase (1), a transitional phase (2), and the pachytene phase (3). The folt- 1 knockout reproductive tract on the top is much smaller, but nuclei in the three phases are present. The nuclei were visualized under epifluorescence after DAPI labeling.

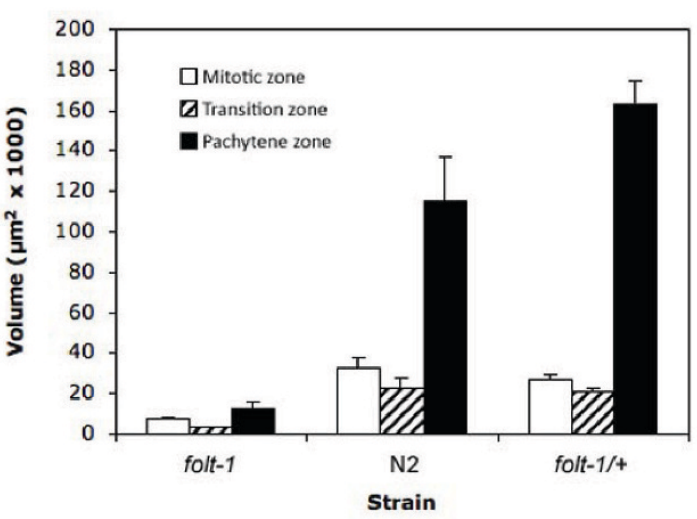

Figure 4 Volumes of the three zones of the reproductive tracts of folt-1 knockout mutants, N2, and folt-1/+ heterozygote hermaphrodites. Error bars represent 1 SEM.

if they might have extended lifespans [34,35]. Our lifespan results ran counter to the hypothesis: folt-1 knockout worms had significantly shorter life spans of 9.4 \pm 0.4 (SEM) days compared to N2 worms which lived 16.9 \pm 0.7 days $(t=9.07 ; P<0.001$; Fig. 9$)$. The decrease in average life span due to the folt-1 knockout was $45 \%$. Therefore, in addition to its effects on the germline, our lifespan and defecation results indicate that the folt-1 gene plays a role in the soma.

\section{Discussion}

The folt-1(ok1460) knockout mutation affects both the soma and the germline. Mutant hermaphrodites defecate slower, live significantly shorter lives, have reduced ger-

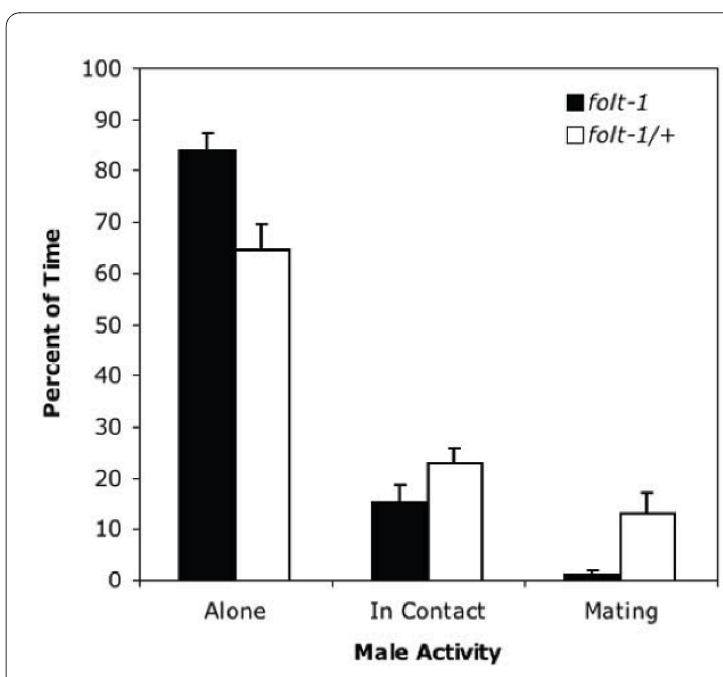

Figure 5 The mating efficiency of folt- 1 knockout males compared to folt-1/+ heterozygous males. The activity of single males confined with 10 wild type hermaphrodites was observed at five minute intervals for an hour. Homozygous folt- 1 knockout males were observed to be alone a greater percentage of our observations, and to be mating much less than were folt-1/+ heterozygotes. 

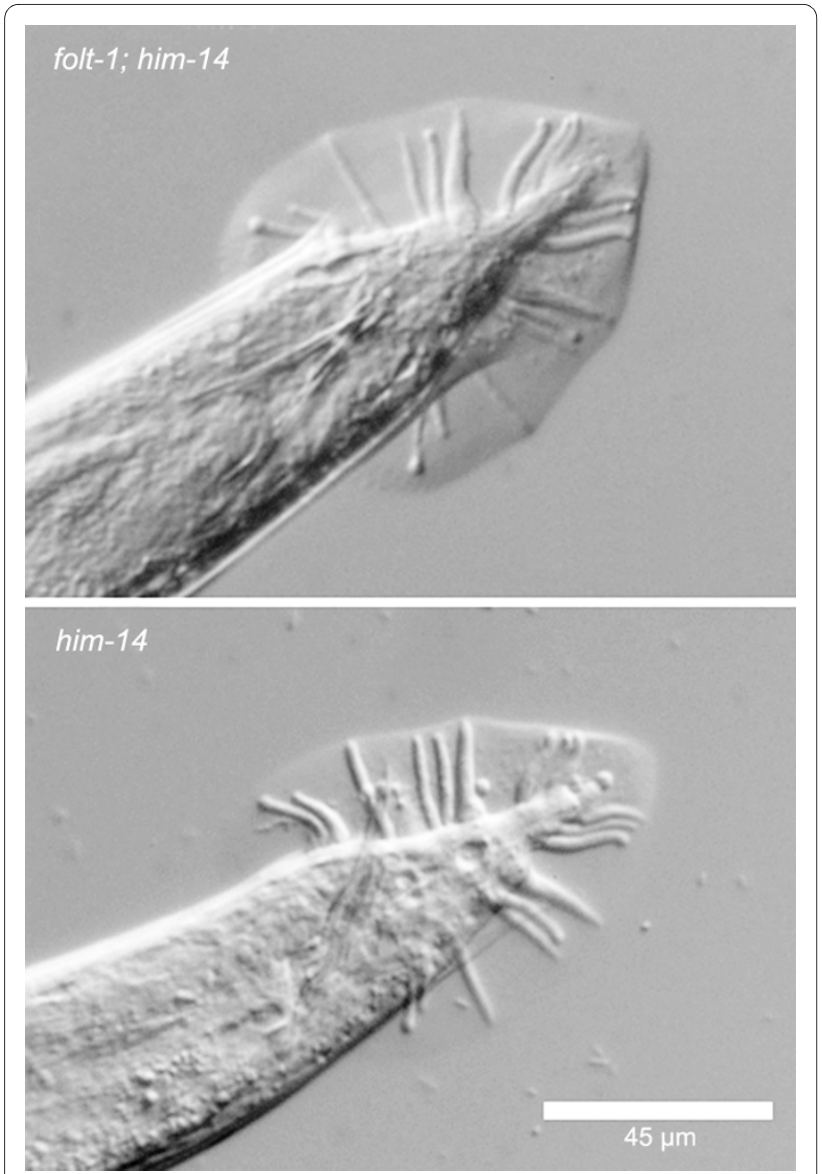

Figure 6 The copulatory bursae from the tails of both folt-1; him14, and him-14 males. There was no observable difference between the tails of the two genotypes.

mline proliferation, produce small numbers of sperm and are oogenesis defective. These findings suggest that folt-1 is expressed in multiple tissues. Using a transcriptional folt-1::GFP fusion, Balamurugan et al [27] demonstrated that folt-1 is expressed primarily in the posterior intestine and pharynx of the digestive system but also in numerous muscles. The germline defects we describe here implicate the gonadal tissue as an additional site of folt-1 expression, but microarray data indicate that folt- 1 is not upregulated in the germline [36]. In a large-scale analysis of gene expression in C. elegans using GFP transcriptional fusions, Hunt-Newbury et al. [37] showed that folt-1 is expressed in the gonadal sheath cells. These muscular cells are known to move the oocytes out of the ovary and into the sperm storage chamber during ovulation [38], but they also form gap junctions with the oocytes [39] providing a possible route for folate into the developing germ cells. It is interesting that the reproductive tracts of folt-1 knockout hermaphrodites appear remarkably similar to those that develop after the larval ablation of the gonadal sheath/spermathecal precursor cells as shown by

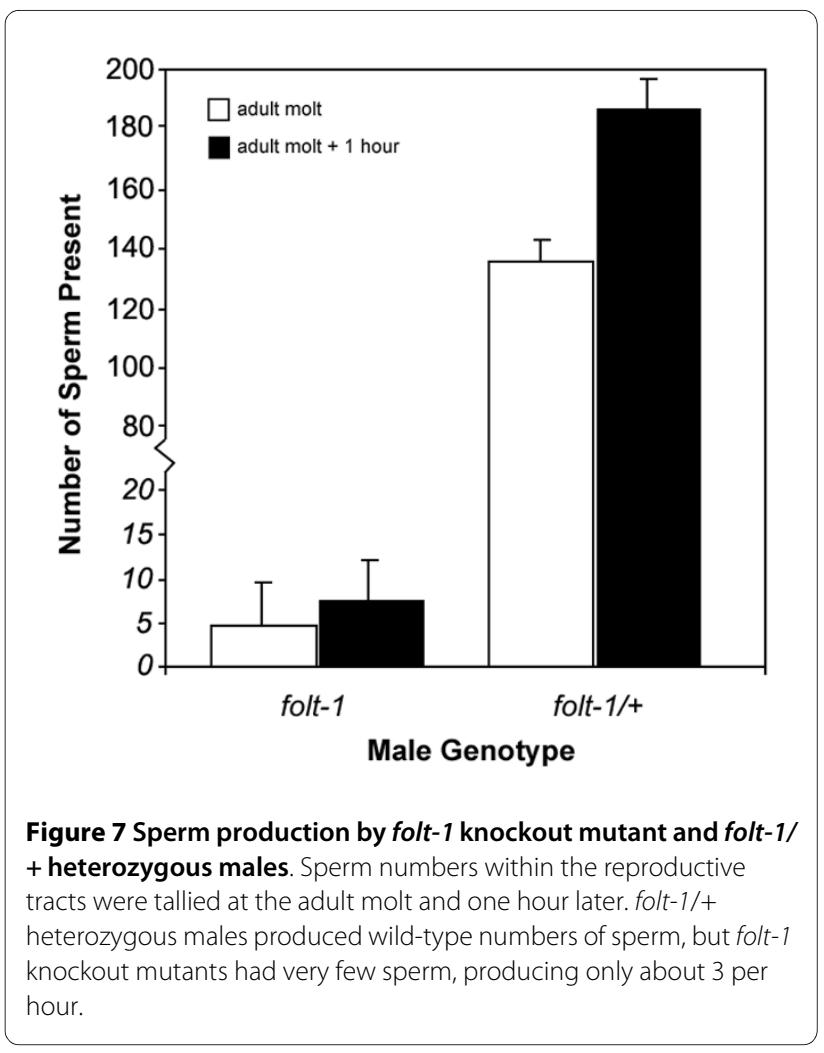

McCarter et al. [40]. Perhaps the germline proliferation defect induced by ablation of the sheath cell lineage is due to its effect on folate transport into the germline.

While the gonadal sheath cells may be the conduit into the germline, it is unclear how the folate deficit associated with the folt-1(ok1460) knockout results in defective proliferation. Germline proliferation is controlled by cells

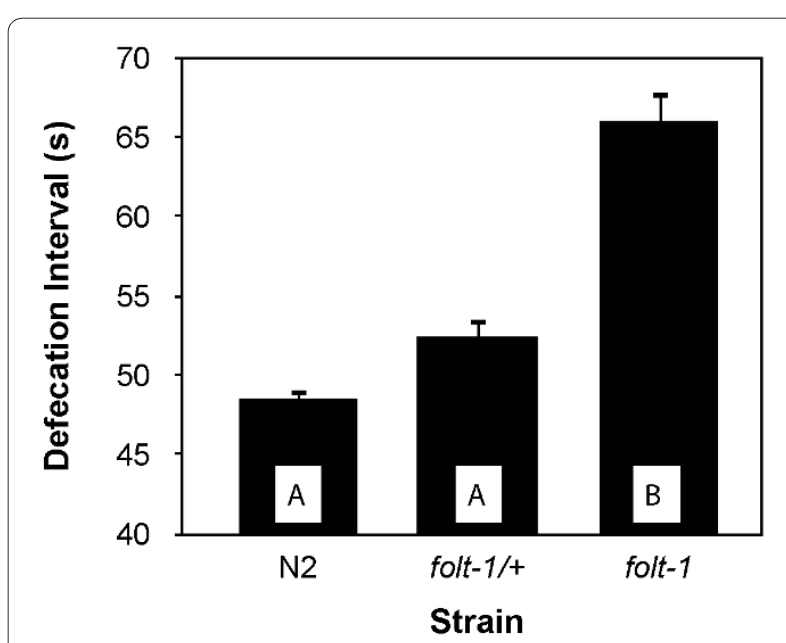

Figure 8 The time interval between defecations for folt- 1 knock out worms, folt-1/+ heterozyogotes, and wild type worms from the strain N2. Error bars represent 1 SEM, and bars sharing letters are not significantly different at $P=0.05$ by Bonferroni post hoc analysis. 


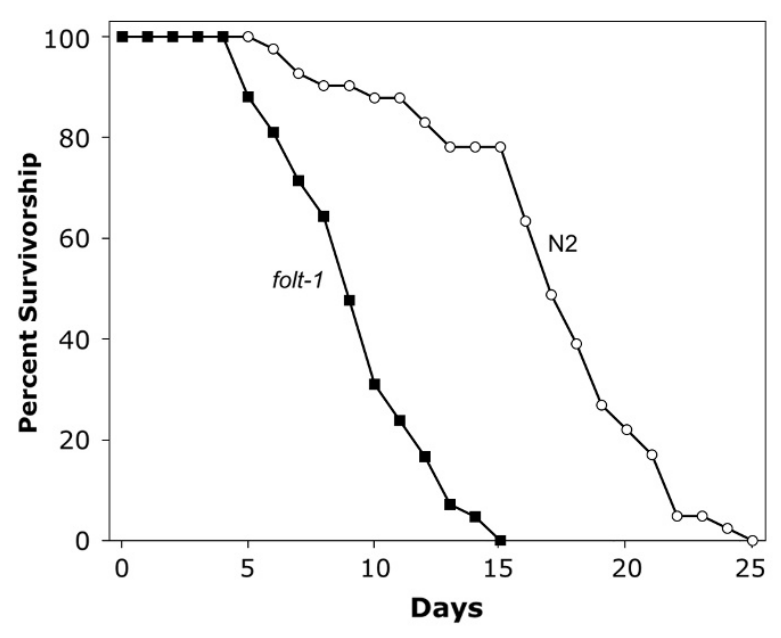

Figure 9 The survivorship of folt-1 knockout mutant worms compared to that of $\mathrm{N} 2$ worms

at the distal tips of the gonad arms. These distal tip cells maintain the mitotic stem cell population of nuclei through a Notch family signaling pathway [41]. At this point, it is unclear whether folate is affecting Notch signaling from the distal tip cells to the mitotic cells in $C$. elegans, but in vertebrates, low folate levels are known to modulate intracellular signaling [42]. In mice, knockout of the orthologous gene (Slc19a1) results in sterility due to embryonic failure at a very early stage $[24,25]$. Taparia et al. [25] hypothesize that folate deficiency in mice causes a buildup of homocysteine which in turn causes an immune response to folate receptor 1 (Folr1). In support of this hypothesis, potentially folate deficient women who had pregnancies complicated by neural tube defects tended to have autoantibodies toward their folate receptors [43]. Such a mechanism could not occur in C. elegans because they have neither a folate receptor ortholog [27], nor a mammalian immune system. Alternatively, folate affects DNA methylation [4], and DNA methylation is an important form of gene regulation in the soma of vertebrate embryos [5]. DNA methylation cannot explain our results, because it is not found in C. elegans and other nematodes [44]. The remaining known scenarios by which the folt-1(ok1460) knockout could induce sterility involve the production of nucleotides and amino acids [13]. Deficits in DNA synthesis and/or gene expression would likely be manifest in the gonad, the only site of cell division in the adult worm, and proliferation of germ nuclei is significantly reduced in folt-1 knockout worms.

C. elegans has been extensively used as an animal model for studying the effect of different factors/conditions on aging [45] and metabolism [46,42,47]. In this study we found that folate deficiency induced by the folt1 knockout reduces lifespan and slows defecation, a behavior sensitive to metabolic rate [33]. Furthermore, knockout males are poor maters, even though their copulatory organs appear normal, likely reflecting a slowed metabolism and/or additional somatic defects. These effects may also be due to the critical role of folate in the biosynthesis of purines, pyrimidines, and certain amino acids. However, comparing the folt-1 knockout phenotype to those of other mutants suggests alternative explanations. Many mutations that slow metabolism tend to extend lifespan [48,49], but a few metabolic mutations reduce longevity [50] as does the folt-1(ok1460) mutation. For example, longevity is reduced by a mutation in mev-1, which encodes a subunit of cytochrome $b_{560}$ [51,52], and mutant worms are thought to have higher levels of reactive oxygen species. In addition, the $u a D f 5$ mitochondrial deletion reduces both metabolic rate and lifespan [53], and we have shown that worms harboring the $u a D f 5$ deletion have increased ROS (CWL, unpublished). Perhaps folt-1 knockout worms have increased ROS as well, although this issue awaits further study.

\section{Conclusions}

Our results suggest that folate deficiency in C. elegans caused by the folt-1(ok1460) mutation produces an overall decline in worm fitness and a defect in germline proliferation. Folate deficiency produces defects in oogenesis in humans [54], mice [55], the fruit fly D. melanogaster [26]. We show here that folate deficiency reduces production of sperm and nearly eliminates oogenesis in the nematode C. elegans. While the specific mechanisms for the defects remain unclear, there appears to be a general requirement for folate during oogenesis in animals.

\section{Methods \\ Worm handling}

Worm strains were maintained on Nematode Growth Media (NGM) agar plates seeded with Escherichia coli bacteria OP50 [56]. Experiments were conducted at $20^{\circ} \mathrm{C}$ unless noted otherwise. The C. elegans strain N2 was used as the wild-type control. The him-14(it144)II and folt-1(ok1460)V/nT1 [qIs51](IV;V) strains were obtained from the Caenorhabditis Genetics Center (CGC, Minneapolis, MN). Unmated him-14 mutant hermaphrodites produce a relatively high proportion of male progeny. The folt-1(ok1460)V/nT1 [qls51](IV;V) strain was originally provided by the C. elegans Reverse Genetics Core Facility at UBC, which is part of the International C. elegans Gene Knockout Consortium (Oklahoma Medical Research Foundation, Oklahoma City, OK). This strain bears the ok1460 deletion allele balanced by the $n T 1$ translocation that is itself marked with the qls51 GFP transgene under the myo-2 promoter, which induces pharyngeal expression. The strain was maintained by picking GFP-labeled worms, which are themselves heterozygotes for the ok1460 mutation. Knockout mutants were obtained by 
picking worms without pharyngeal GFP. Knockout males were obtained in one of two ways. First, we picked the rare males produced through non-disjunction of the $\mathrm{X}$ chromosome and mated them to hermaphrodites to establish a male-producing line of folt-1(ok1460) V/nT1 [qls51] $(I V ; V)$, which had to be propagated by setting up matings every generation. Second, we constructed the strain him-14(it144)II; folt-1(ok1460)V/nT1 [qls51](IV;V), which generates males from unmated hermaphrodites through increased rates of non-disjunction. The fer1(hc13ts) was obtained from Samuel Ward at University of Arizona; fer-1(hc13ts) mutant hermaphrodites are sterile at $25^{\circ} \mathrm{C}$ due to a sperm defect.

\section{Microscopy for Sperm Counts, Reproductive Tract Morphometry, and Germline Apoptosis}

Worms were observed under DIC optics for structural examination, especially inspection of the tail morphology of folt-1 knockout males. To count sperm within worms, we fixed them, labeled their DNA with DAPI (4'6-diamidino-2-phenylindole), and observed them under epifluorescence [53]. DAPI labeled sperm nuclei are characteristically compact in nature, making them easy to identify and count. This technique was used to count sperm produced by folt-1 knockout hermaphrodites and males, and it was used to determine whether folt-1 knockout hermaphrodites had received sperm from males at mating. DNA labeling was also used in a morphometric analysis of the reproductive tract of mutant worms. One day after they were picked as L4 larvae, knockout mutant hermaphrodites and control worms were dissected under Sperm Medium [57] containing 10 $\mu \mathrm{g} / \mathrm{ml}$ Hoechst 33342, a DNA label similar to DAPI, but able to penetrate living tissue. The reproductive tracts were imaged and the nuclear characteristics used to define the mitotic, pachytene, and transitional regions of the tracts. The regions were measured using OpenLab ${ }^{\mathrm{Tu}}$ imaging software, and their cylindrical volumes calculated. Finally, we examined the hermaphrodite germline for apoptosis using an assay involving the dye SYTO12 (Molecular Probes') as described by Gumienny et al. [29]. Briefly, one day after isolation as L4 larvae, adult hermaphrodites were exposed for 4-5 hours to a $33 \mu \mathrm{M}$ aqueous solution mix of SYTO12 and $10 \mu \mathrm{g} / \mathrm{ml}$ Hoechst 33342. Subsequently, these animals were transferred to seeded plates for 30-60 minutes to remove stained bacteria from their guts. Lastly, the worms were mounted on agarose pads and examined under epifluorescence. Apoptotic nuclei are labeled by SYTO12.

\section{Lifespan and Defecation}

Worm lifespan was measured with age-synchronous animals from the time they were eggs until their death. To obtain age-synchronized cohorts of worms, adult her- maphrodites were allowed to lay eggs for two hours in 35 $\mathrm{mm}$ Petri dishes. The resulting eggs were allowed to hatch and the worms grown at $20^{\circ} \mathrm{C}$. During their fertile period, the worms were transferred to new plates daily in order to distinguish them from their progeny. Worms were examined every day until death and were scored as dead when they were no longer able to move, even in response to touch. Defecation interval was determined by observing worms for the obvious posterior body contractions that load the rectum for defecation [58]. We measured three defecation intervals for each worm and took the mean.

\section{Statistical Analyses}

All statistical analyses were conducted using PASW Statistics 17.0. Pairs of means were analyzed with $t$-Tests, whereas data sets with 3 or more means were analyzed by ANOVA, with post-hoc comparison of pairs of means with either Bonferroni or Fisher's LSD tests.

\section{Authors' contributions}

MUA and WSL contributed to experimental design, data collection, and manuscript preparation. $\mathrm{KB}$ and $\mathrm{BA}$ participated in the conception and design of the projects as well as manuscript preparation. HMS contributed to experimental design, data interpretation, and manuscript preparation. Finally, CWL took part in designing and conducting the experiments, analyzing the data, and preparing the manuscript. All authors read and approved the final manuscript.

\section{Acknowledgements}

We thank Aidyl Gonzalez-Serricchio for technical assistance. Some C. elegans strains used in this work were created by the International C. elegans Gene Knockout Consortium and provided by the Caenorhabditis Genetics Center, which is funded by the NIH National Center for Research Resources (NCRR). This research was funded by grants from the U.S. National Institutes of Health (Awards 1 SC3 GM087212-01 and 5 S06 GM053933-10 to CWL and award DK075348 to HMS), from the California State University Agricultural Initiative (Award 07-4-156-12 to CWL), and from Department of Veteran Affairs (to HMS).

\section{Author Details}

'Department of Biological Sciences, California State University Pomona, CA 91768, USA, ${ }^{2}$ Current Address: Department of Chemistry and Biochemistry, University of California, Los Angeles, CA 90095, USA, ${ }^{3}$ Veterans Affairs Medical Center, Long Beach, CA 90822, USA, ${ }^{4}$ Departments of Medicine and Physiology/Biophysics, University of California, Irvine, CA 92697, USA and ${ }^{5}$ Current Address: Department of Biotechnology, Alagappa University, Karaikudi 630 003, India

Received: 26 February 2010 Accepted: 4 May 2010

Published: 4 May 2010

\section{References}

1. Blakley RL, Whitehead VA: Folates and Pterins. Nutritional, Pharmacological and Physiological Aspect. New York: John Wiley and Sons; 1986.

2. Stokstad ELR: Historical perspective on key advances in the biochemistry and physiology of folates. In Folic Acid Metabolism in Health and Disease Edited by: Picciano MF, Stokstad ELR, Gregory JF. New York: Wiley-Liss; 1990:1-21.

3. Titus SA, Moran RG: Retrovirally mediated complementation of the glyB phenotype. Cloning of a human gene encoding the carrier for entry of folates into mitochondria. J Biol Chem 2000, 275:36811-7.

4. Beaudin AE, Stover PJ: Folate-mediated one-carbon metabolism and neural tube defects: balancing genome synthesis and gene expression. Birth Defects Res C Embryo Today 2007, 81:183-203. 
5. Bai S, Ghoshal K, Datta J, Majumder S, Yoon SO, Jacob ST: DNA methyltransferase $3 \mathrm{~b}$ regulates nerve growth factor-induced differentiation of $\mathrm{PC} 12$ cells by recruiting histone deacetylase 2 . $\mathrm{Mol}$ Cell Biol 2005, 25:751-66.

6. Brzezinska A, Winska P, Balinska M: Cellular aspects of folate and antifolate membrane transport. Acta Biochim Po/ 2000, 47:735-49.

7. Antony AC: Folate receptors. Annu Rev Nutr 1996, 16:501-21.

8. Sirotnak FM, Tolner B: Carrier-mediated membrane transport of folates in mammalian cells. Annu Rev Nutr 1999, 19:91-122.

9. Qiu A, Jansen M, Sakaris A, Min SH, Chattopadhyay S, Tsai E, Sandoval C, Zhao R, Akabas MH, Goldman ID: Identification of an intestinal folate transporter and the molecular basis for hereditary folate malabsorption. Cell 2006, 127:917-28.

10. Ifergan I, Jansen G, Assaraf YG: The reduced folate carrier (RFC) is cytotoxic to cells under conditions of severe folate deprivation. RFC as a double edged sword in folate homeostasis. J Biol Chem 2008, 283:20687-95

11. Daly LE, Kirke PN, Molloy A, Weir DG, Scott JM: Folate levels and neural tube defects. Implications for prevention. JAMA 1995, 274:1698-702.

12. Wickramasinghe $S N$ : The wide spectrum and unresolved issues of megaloblastic anemia. Semin Hematol 1999, 36:3-18.

13. Boushey CJ, Beresford SA, Omenn GS, Motulsky AG: A quantitative assessment of plasma homocysteine as a risk factor for vascular disease. Probable benefits of increasing folic acid intakes. JAMA 1995 274:1049-57.

14. Rimm EB, Willett WC, Hu FB, Sampson L, Colditz GA, Manson JE, Hennekens C, Stampfer MJ: Folate and vitamin B6 from diet and supplements in relation to risk of coronary heart disease among women. JAMA 1998, 279:359-64.

15. Choi SW, Mason JB: Folate and carcinogenesis: an integrated scheme. J Nutr 2000, 130:129-32.

16. Czeizel AE, Dudas I: Prevention of the first occurrence of neural-tube defects by periconceptional vitamin supplementation. N Eng/ J Med 1992, 327:1832-5

17. Werler MM, Shapiro S, Mitchell AA: Periconceptional folic acid exposure and risk of occurrent neural tube defects. JAMA 1993, 269:1257-61.

18. De Marco P, Calevo MG, Moroni A, Merello E, Raso A, Finnell RH, Zhu H, Andreussi L, Cama A, Capra V: Reduced folate carrier polymorphism (80A-->G) and neural tube defects. Eur J Hum Genet 2003, 11:245-52.

19. De Marco P, Calevo MG, Moroni A, Arata L, Merello E, Cama A, Finnell RH, Andreussi L, Capra V: Polymorphisms in genes involved in folate metabolism as risk factors for NTDs. Eur J Pediatr Surg 2001, 11(Suppl 1):S14-7.

20. Shaw GM, Lammer EJ, Zhu H, Baker MW, Neri E, Finnell RH: Maternal periconceptional vitamin use, genetic variation of infant reduced folate carrier (A80G), and risk of spina bifida. Am J Med Genet 2002 108:1-6.

21. Shaw GM, Zhu H, Lammer EJ, Yang W, Finnell RH: Genetic variation of infant reduced folate carrier (A80G) and risk of orofacial and conotruncal heart defects. Am J Epidemiol 2003, 158:747-52.

22. Relton CL, Wilding CS, Pearce MS, Laffling AJ, Jonas PA, Lynch SA, Tawn EJ, Burn J: Gene-gene interaction in folate-related genes and risk of neural tube defects in a UK population. J Med Genet 2004, 41:256-60.

23. Mattson MP, Shea TB: Folate and homocysteine metabolism in neural plasticity and neurodegenerative disorders. Trends Neurosci 2003, 26:137-46.

24. Zhao R, Russell RG, Wang Y, Liu L, Gao F, Kneitz B, Edelmann W, Goldman ID: Rescue of embryonic lethality in reduced folate carrier-deficient mice by maternal folic acid supplementation reveals early neonatal failure of hematopoietic organs. J Biol Chem 2001, 276:10224-8.

25. Taparia S, Gelineau-van Waes S, Rosenquist TH, Finnell RH: Importance of folate-homocysteine homeostasis during early embryonic development. Clin Chem Lab Med 2007, 45:1717-27.

26. Affleck JG, Neumann K, Wong L, Walker VK: The effects of methotrexate on Drosophila development, female fecundity, and gene expression. Toxicol Sci 2006, 89:495-503.

27. Balamurugan K, Ashokkumar B, Moussaif M, Sze JY, Said HM: Cloning and functional characterization of a folate transporter from the nematode Caenorhabditis elegans. Am J Physiol Cell Physiol 2007, 293:C670-81.

28. Hubbard EJ, Greenstein D: The Caenorhabditis elegans gonad: a test tube for cell and developmental biology. Dev Dyn 2000, 218:2-22.
29. Gumienny TL, Lambie E, Hartwieg E, Horvitz HR, Hengartner MO: Genetic control of programmed cell death in the Caenorhabditis elegans hermaphrodite germline. Development 1999, 126:1011-22.

30. Achanzar WE, Ward S: A nematode gene required for sperm vesicle fusion. J Cell Science 1997, 110:1073-1081.

31. Hodgkin J: Male phenotypes and mating efficiency in Caenorhabditis elegans. Genetics 1983, 103:43-64

32. LaMunyon CW, Ward S: Larger sperm outcompete smaller sperm in the nematode Caenorhabditis elegans. Proc R Soc Lond B 1998, 265:1997-2002.

33. Branicky R, Hekimi S: What keeps $\mathrm{C}$. elegans regular: the genetics of defecation. Trends Genet 2006, 22:571-9.

34. Arantes-Oliveira N, Apfeld J, Dillin A, Kenyon C: Regulation of life-span by germ-line stem cells in Caenorhabditis elegans. Science 2002, 295:502-5.

35. Van Voorhies WA: Production of sperm reduces nematode lifespan. Nature 1992, 360:456-458.

36. Reinke V, Gil IS, Ward S, Kazmer K: Genome-wide germline-enriched and sex-biased expression profiles in Caenorhabditis elegans. Development 2004, 131:311-23.

37. Hunt-Newbury R, Viveiros R, Johnsen R, Mah A, Anastas D, Fang L, Halfnight $E$, Lee $D$, Lin J, Lorch A, et al:: High-throughput in vivo analysis of gene expression in Caenorhabditis elegans. PLoS Biol 2007, 5:e237.

38. Greenstein D: Control of oocyte meiotic maturation and fertilization. In WormBook The C elegans Research Community; 2005.

39. Rose KL, Winfrey VP, Hoffman LH, Hall DH, Furuta T, Greenstein D: The POU gene ceh-18 promotes gonadal sheath cell differentiation and function required for meiotic maturation and ovulation in Caenorhabditis elegans. Dev Biol 1997, 192:59-77.

40. McCarter J, Bartlett B, Dang T, Schedl T: Soma-germ cell interactions in Caenorhabditis elegans: multiple events of hermaphrodite germline development require the somatic sheath and spermathecal lineages. Dev Biol 1997, 181:121-43.

41. Kimble J, Crittenden SL: Germline proliferation and its control. In Book Germline proliferation and its control The C. elegans Research Community ed. City: WormBook

42. Crott JW, Liu Z, Keyes MK, Choi SW, Jang H, Moyer MP, Mason JB: Moderate folate depletion modulates the expression of selected genes involved in cell cycle, intracellular signaling and folate uptake in human colonic epithelial cell lines. J Nutr Biochem 2008, 19:328-35.

43. Rothenberg SP, da Costa MP, Sequeira JM, Cracco J, Roberts JL, Weedon J, Quadros EV: Autoantibodies against folate receptors in women with a pregnancy complicated by a neural-tube defect. NEng/ J Med 2004, 350:134-42.

44. Gutierrez A, Sommer RJ: Evolution of dnmt-2 and mbd-2-like genes in the free-living nematodes Pristionchus pacificus, Caenorhabditis elegans and Caenorhabditis briggsae. Nucleic Acids Res 2004, 32:6388-96

45. Golden TR, Melov S: Gene expression changes associated with aging in C. elegans. In Book Gene expression changes associated with aging in $C$. elegans The C. elegans Research Community ed. City: WormBook.

46. Fei YJ, Liu JC, Inoue K, Zhuang L, Miyake K, Miyauchi S, Ganapathy V: Relevance of NAC-2, an Na+-coupled citrate transporter, to life span, body size and fat content in Caenorhabditis elegans. Biochem J 2004, 379:191-8.

47. Lee BH, Ashrafi K: A TRPV channel modulates C. elegans neurosecretion, larval starvation survival, and adult lifespan. PLoS Genet 2008, 4:e1000213.

48. Van Voorhies WA, Ward S: Genetic and environmental conditions that increase longevity in Caenorhabditis elegans decrease metabolic rate. Proc Natl Acad Sci USA 1999, 96:11399-403.

49. Van Voorhies WA: Is life span extension in single gene long-lived Caenorhabditis elegans mutants due to hypometabolism? Exp Gerontol 2003, 38:615-8.

50. Braeckman BP, Houthoofd K, Vanfleteren JR: Patterns of metabolic activity during aging of the wild type and longevity mutants of Caenorhabditis elegans. Age 2000, 23:55-73.

51. Ishii N, Fujii M, Hartman PS, Tsuda M, Yasuda K, Senoo-Matsuda N, Yanase $S$, Ayusawa D, Suzuki K: A mutation in succinate dehydrogenase cytochrome $b$ causes oxidative stress and ageing in nematodes. Nature 1998, 394:694-7. 
52. Ishii N, Takahashi K, Tomita S, Keino T, Honda S, Yoshino K, Suzuki K: A methyl viologen-sensitive mutant of the nematode Caenorhabditis elegans. Mutat Res 1990, 237:165-71.

53. Liau W-S, Gonzalez-Serricchio A, Deshommes C, Chin K, LaMunyon CW: A persistent mitochondrial deletion reduces fitness and sperm performance in heteroplasmic populations of $C$. elegans. BMC Genetics 2007, 8:8.

54. Thaler CJ, Budiman $H$, Ruebsamen $H$, Nagel D, Lohse P: Effects of the common $677 \mathrm{C}>\mathrm{T}$ mutation of the 5,10-methylenetetrahydrofolate reductase (MTHFR) gene on ovarian responsiveness to recombinant follicle-stimulating hormone. Am J Reprod Immunol 2006, 55:251-8.

55. Hansmann I: Chromosome aberrations in metaphase II-oocytes. Stage sensitivity in the mouse oogenesis to amethopterin and cyclophosphamide. Mutat Res 1974, 22:175-91.

56. Brenner S: The genetics of Caenorhabditis elegans. Genetics 1974, 77:71-94.

57. Nelson GA, Ward S: Vesicle fusion, pseudopod extension and amoeboid motility are induced in nematode spermatids by the ionophore monensin. Cell 1980, 19:457-64

58. Walker DS, Gower NJ, Ly S, Bradley GL, Baylis HA: Regulated disruption of inositol 1,4,5-trisphosphate signaling in Caenorhabditis elegans reveals new functions in feeding and embryogenesis. Mol Biol Cell 2002, 13:1329-37.

59. Zalevsky J, MacQueen AJ, Duffy JB, Kemphues KJ, Villeneuve AM: Crossing over during Caenorhabditis elegans meiosis requires a conserved MutSbased pathway that is partially dispensable in budding yeast. Genetics 1999, 153:1271-83.

doi: 10.1186/1471-213X-10-46

Cite this article as: Austin et al., Knockout of the folate transporter folt-1 causes germline and somatic defects in C. elegans BMC Developmental Bio/ogy 2010, 10:46

Submit your next manuscript to BioMed Central and take full advantage of:

- Convenient online submission

- Thorough peer review

- No space constraints or color figure charges

- Immediate publication on acceptance

- Inclusion in PubMed, CAS, Scopus and Google Scholar

- Research which is freely available for redistribution

Submit your manuscript at www.biomedcentral.com/submit
C) Biomed Central 